\title{
Effectiveness of information booklet on knowledge regarding home management of selected common illness in children
}

\author{
Chetan Kumar Rathore ${ }^{1}$, Arpan Pandya ${ }^{2}$, Ravindra H.N. ${ }^{3}$

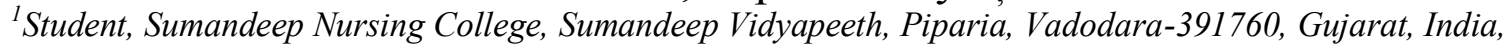 \\ ${ }^{2}$ Lecturer, Department Of Child Health Nursing, Sumandeep Nursing College, Sumandeep Vidyapeeth, Piparia, \\ Vadodara-391760, Gujarat, India, \\ ${ }^{3}$ Principal, Sumandeep Nursing College, Sumandeep Vidyapeeth, Piparia, Vadodara-391760, Gujarat, India.
}

\begin{abstract}
:
Background: Child care is mostly the responsibility of mothers. Therefore, the mother's knowledge about child care influences the nature and quality of care that is given to the child. Several studies have revealed that the mothers' level of education has a positive impact on her knowledge and how she deals with child health care issues.
\end{abstract}

Aims and objectives: The study aimed at assessing knowledge of mothers regarding home management of selected common illness in children, evaluate the effectiveness of information booklet on knowledge regarding home management of selected common illness in children and find out the association between the post test scores with selected demographic variables.

Material and Methods: A one group pre-test post-test pre-experimental design and evaluative approach was adopted. The study was conducted among 60 mothers conveniently selected from amodar village at Vadodara.

Results: The results of the study shows that in pre test, mothers were having on average $44.26 \%$ knowledge regarding selected common illness of children and mean score was $25.8 \pm 3.96$ in post test, average $75.88 \%$

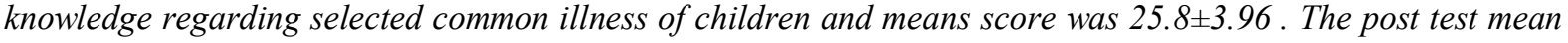
knowledge score is significantly greater than the pre-test mean knowledge score so information booklet was effective.

Conclusion: This study concluded that self instructional module was highly effective in improving knowledge of mothers regarding home management of common illness in children.

Key words: Assess, Information booklet, Effectiveness, Knowledge, home management, Common illness, under five mothers, Children.

\section{Introduction}

Health is both a responsibility as well as right. Protecting the health and development of children is a long-term contribution to the growth and development of the country as a whole. Children under five years of age constitute to $15-20 \%$ of the India's population. Their protection is a greatest investment for country's economic prosperity and political stability. ${ }^{[1]}$

The most of the children who die each year could be saved by low technology, evidence based, cost effective measures such as vaccines, antibiotic micronutrients supplementation, improved family care and breastfeeding praction and oral rehydration therapy. In addition to providing vaccines and antibiotics to children, education could also be provided to mothers about how they makes simple changes to living conditions such as improving hygiene in order to increase the health of her children. ${ }^{[2]}$

Every year, more than 10 million children less than 5 years of age, die developing countries. Most of these deaths are preventable and are mainly due to infective etiologies like diarrhoea, respiratory tract infections, measles, malaria, AIDS, tuberculosis etc. Apart from malnutrition, the other factors contributing to illnesses in this age group are poor living conditions, unsafe drinking water, poor hygiene and overcrowding. ${ }^{[3]}$

In India diarrhoeal disease is a major public health problem among children under the age of 5 years health institutions up to a third of total pediatric admission are due to diarrhoeal diseases and up to $17 \%$ of all death in indoor pediatric patients is diarrhoea related. ${ }^{[4]}$

Diarrhoeal diseases are one of the leading causes for under - five children's morbidity and mortality. One of the important objective of the Child Survival and Safe Motherhood Programme was to reduce 30 per cent of Diarrhoeal related deaths in children under the age of five years by 2000 and 70 per cent by $2005 .^{[5]}$

The mortality rate of acute respiratory tract infections among children below 5 years. This study estimated that nearly 6.1 percentage of child mortality per year in children below 5 years. Statistically the crude mortality rate was 14.3 per 1,000 children $0-4$ years old, with a corresponding acute respiratory tract infections 
specific mortality rate of 8.9 per 1,000 . The prevalence of viral infection was 32.8 and that of bacteremic AURI was 6.7 per 1,000 children with moderate AURI. ${ }^{[6]}$

\section{Statement Of The Problem}

"A study to assess the effectiveness of information booklet on knowledge regarding home management of selected common illness in children among mothers at selected rural areas of Vadodara."

\section{Objectives Of The Study}

1. Assess the existing knowledge of mothers regarding home management of selected common illness in children.

2. Evaluate the effectiveness of information booklet on knowledge regarding home management of selected common illness in children.

3. Find out the association between the post test scores and selected demographic variables such as age, religion, educational qualification, family income, number of children, and source of knowledge .

\section{Hypotheses}

H1: There will be significant difference between pre-test and post-test knowledge scores among mothers regarding home management of selected common illness in children.

H2: There will be significant association between post-test scores and selected demographic variables.

\section{Materials And Methods}

Research Approach: Evaluative research approach was used.

Research Design: A one group pre-test post-test Pre experimental research design was adopted

Setting of the Study: The study was conducted in amodar village of Vadodara.

Target Population: The target population for this study consisted of under five mothers.

Sample: The sample for the present study comprises of 60 under five mothers from Amodar village of Vadodara.

Sampling technique: Non-probability convenience sampling technique was used to select the sample for this study.

Development of tool for data collection: it consists of 2 parts:-

The researcher prepared a Self Reportive Structured Interview questionnaire is used as tool for the

study. The Self Reportive Structured Interview tool consists of two parts

Part A: It is designed to obtain general information of the respondents and it consists of six items related to the demographic variables of the primary school teachers.

Part B: It consists of thirty four items regarding knowledge of mothers regarding selected common illness of children.

Validity of instrument: The Self Reportive Structured Interview tool and self instructional module were given to 12 experts along with the blue print and objectives of the study to establish the content validity of the tool and SIM regarding selected common illness of children. The experts were from the field of Nursing and Medical, Research department. They were requested to give their opinion and suggestions regarding the relevancy of the items in the tool.

Reliability: After obtaining formal administrative permission the Gujarat and English version of the tool was administered to 6 samples selected as per the set criteria. The scores were calculated and then given for statistical analysis. The reliability was established by using split half method.

Data collection procedure: A formal permission was obtained from the Amodar village of Vadodara district. Data was collected from November $18^{\text {th }}$ to December $02^{\text {nd }} 2013$. After identifying the samples objectives of the study were discussed and consent for the participation in the study was taken from the selected group. The investigator assured the subjects about the confidentiality of the data. The investigator herself administered the questionnaire for the pre-test.

\section{Analysis of data}

Both descriptive and inferential statistics analyzed on the basis of the objectives and hypotheses of the study. The knowledge of mothers regarding selected common illness of children assessed before and after the administration of SIM would be calculated using frequency, mean, and standard deviation and inferential statistics used to analyze Paired ' $t$ ' test. The data was also presented graphically and in the form of table. 


\section{Results}

The analysis is made on the basis of objectives and hypothesis. The data analysis is planned to include descriptive and inferential statistics. Data is analysis in following parts:

Section - A: Description of the demographic variables of mothers

Section - B: Analysis of knowledge scores mothers.

Section- C: Analysis of difference between the pre -test and post-test knowledge scores of mothers regarding

home management of selected common illness in children.

Effectiveness of information booklet in terms of:-

-Significance of difference between overall knowledge scores of the mothers.

-Comparison of Pre-test and Post-test knowledge scores of mothers.

Section - D: Association between post - test knowledge scores of the mothers with their selected socio-

demographic variables.

\section{Section I- Results of demographic characteristics:}

- Distribution of respondents in relation to above cited table depicts that majority of mothers $35(58.33 \%)$ were in between the age group of 20-35 years, $21(35 \%)$ of them were below 25 years, $4(6.67 \%)$ were belongs to $30-45$ years and no one found for above 45 years.

- Distribution of respondents in religion represent the all mothers were belongs to Hindu religion.

- Distribution of respondents in relation to educational qualification revealed that that $28(46.67 \%)$ mothers were belongs to primary, as same $28(46.67 \%)$ belongs to higher secondary, $3(5.00 \%)$ of them belongs to graduate, only $1(1.66 \%)$ was belongs to post graduate educational status.

- Distribution of respondents in relation to teaching experience revealed that the majority of mothers $37(61.67 \%)$ had their monthly family income between 5000-10000, 12(20\%) of them had in between 1000 $15000,10(16.67 \%)$ were belongs to below 5000 income, and only $1(1.66 \%)$ have their family income above 15000 .

- Distribution of respondents in relation to religion revealed majority of $30(50 \%)$ have 2 childrens, $29(48.34 \%)$ of them have only one child, only $1(1.66 \%)$ mothers have 3children's in their family.

- Distribution of respondents in the majority of $28(46.67 \%)$ mothers gets their knowledge from mass media, $15(25 \%)$ mothers have knowledge from health personal's, $15(25 \%)$ from their family members and only $2(3.33 \%)$ gets the information's from multiple sources.

Section II: - Analysis Of Knowledge Scores Mothers.

Distribution of pre-test level of knowledge score of mothers based on their knowledge categories.

\begin{tabular}{|l|l|l|l|}
\hline Sr. & Knowledge level & Frequency & Percentage \% \\
No & & & \\
\hline A & Adequate & 2 & 3.33 \\
B & Moderate & 17 & 28.33 \\
C & Inadequate & 41 & 68.34 \\
\hline
\end{tabular}

Section III: Analysis Of Difference Between The Pre -Test And Post-Test Knowledge Scores Of Mothers Regarding Home Management Of Selected Common Illness In Children.

-Significance of difference between overall knowledge scores of mothers

\begin{tabular}{|l|l|c|c|c|c|c|}
\hline $\begin{array}{l}\text { Overall } \\
\text { knowledge } \\
\text { scores }\end{array}$ & $\begin{array}{l}\text { Maximum } \\
\text { Scores }\end{array}$ & Mean & $\begin{array}{l}\text { Standard } \\
\text { deviation }\end{array}$ & $\begin{array}{l}\text { Mean } \\
\text { percentage }\end{array}$ & t-Value & p-value \\
\hline PRE-TEST & 34 & 15.05 & 5.19 & 44.26 & 12.95 & $\begin{array}{c}0.000 \\
, \mathrm{p}<0.05 \\
\mathrm{~S}\end{array}$ \\
\hline POST TEST & 34 & 25.8 & 3.96 & 75.88 & & \\
\hline
\end{tabular}

Comparision of pre-test and post-test knowledge scores of mothers of under five children

\begin{tabular}{|l|l|l|l|}
\hline $\begin{array}{l}\text { Categories Of Knowledge } \\
\text { Score }\end{array}$ & Percentage Range & Pre-Test & Post-Test \\
\hline Adequate & $>75 \%$ & 3.33 & 63.33 \\
\hline Moderate & $50-75$ & 28.33 & 36.67 \\
\hline Inadequate & $<50$ & 68.34 & 00 \\
\hline
\end{tabular}




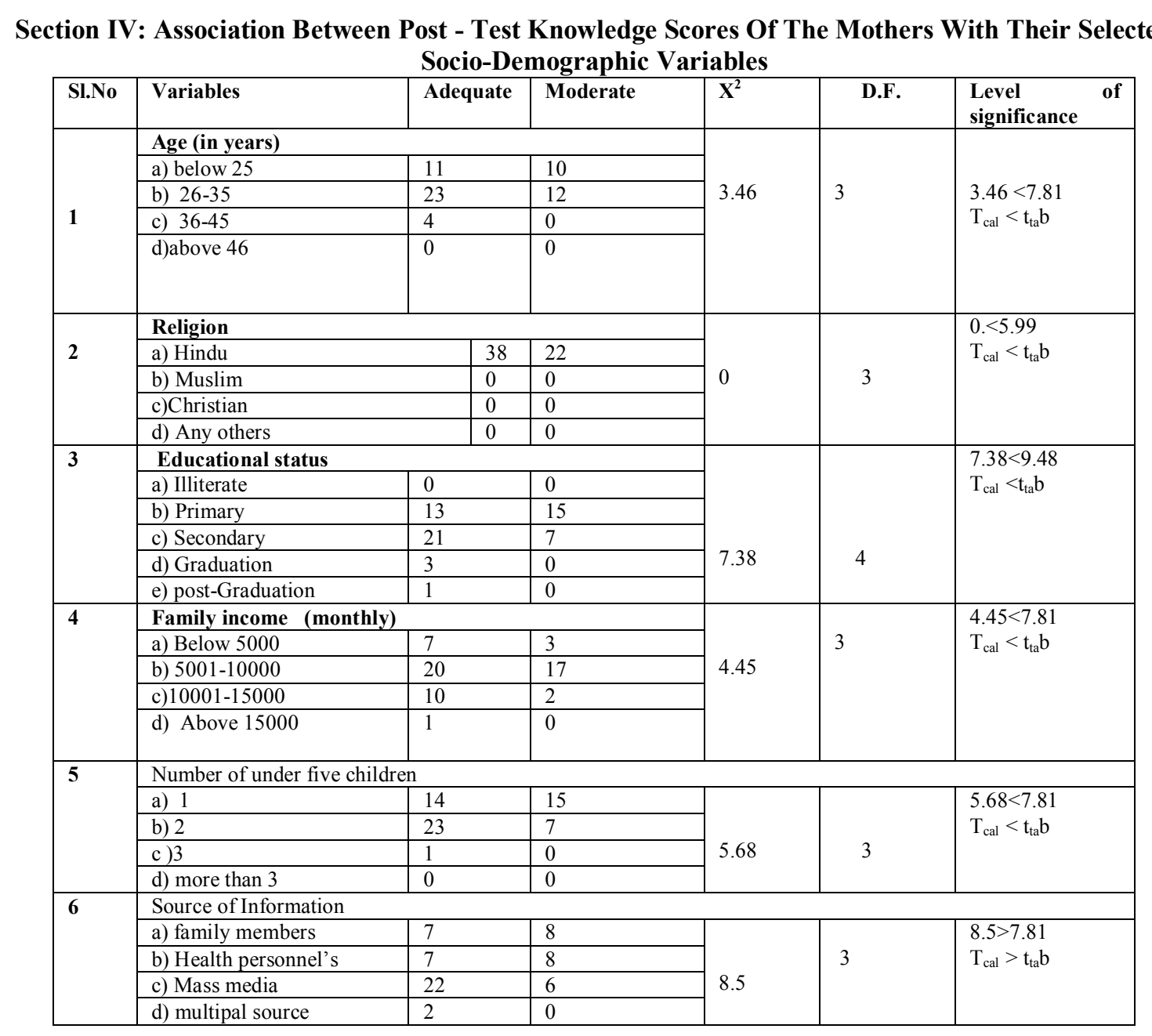

The data in the above cited table; 16 shows that the $\chi 2$ value computed between the knowledge level of mothers regarding home management of common illness in children, and selected socio-demographic variables.

Variables of age $(\chi 2=3.46)$, religion $(\chi 2=0.00)$, education $(\chi 2=7.38)$, family income $(\chi 2=4.45)$, number of under five children's $(\chi 2=5.68)$, was not significant at 0.05 level and only Source of information $(\chi 2=8.5)$, was found significant at 0.05 level of significance.

Thus it can be interpreted that there is a significant association between knowledge of mothers with their source of information, and there is no significant association between knowledge of mothers with selected socio-demographic variables such as age religion, educational status, family income, number of under five year children.

\section{Conclusion}

The findings of this study have been discussed with reference to the objectives and hypothesis. The research approach adopted in the present study is an evaluative research approach with a view to measure the knowledge selected common illness of children. Effectiveness was assessed by analysis of pre test and post test knowledge score to know the effectiveness of information booklet. The data was interpreted by suitable and appropriate statistical method.

\section{Acknowledgement}

I express my gratitude and thanks towards all who have directly or indirectly helped me to complete this study and their support in each major step of the study.

\section{Limitations Of The Study}

The following points were beyond the control of the investigator.

- A limited time available for data collection.

- Sample was selected only from few areas of Vadodara city. 
- The study was confined to 60 subjects, which resulted in reduced power in statistical analysis.

- The study is limited to primary school teachers who are willing to participate in the study..

\section{Recommendations}

Based on the findings of the present study recommendations offered for the future study are:

- Similar study can be conducted on a larger sample.

- A comparative study can be conducted with control group.

- Similar study can be conducted with different population and setting.

- Study can be done to assess the effectiveness of information booklet on knowledge regarding home management of selected common illness in children.

\section{Ethical Standards}

This study was conducted after getting approval from the Institutional Ethics Committee and after obtaining written consents from all subjects.

Source of funding: The authors did not receive any financial support from any third party related to the submitted work.

Conflict of interest: The authors had no relationship/condition/circumstances that present a potential conflict of interest.

\section{References}

[1]. Basavanthappa BT. Community health nursing. $1^{\text {st }}$ ed. New Delhi: Medical Publishers (P) LTD; 2003. p. 298

[2]. S.Sarkar, probiotic therapy for gastro intestinal allergic infants , British food journal 2008,109(6), 481 -492.

[3]. Accordind to WHO children ; reducing mortality Facts sheet No. 178 updated September 2013.

[4]. K.Park.Preventive and Social Medicine.18th edition .india:M/S Bhanarsidas Bhanot Publishers.2005.184

[5]. Mangala S, Gopinath D,Narasimhamurthy N S,Shiv ram C, Impact of education intervention on knowledge of mothers regarding home management of diarrhoea, Indian J Pediatr.2001 Sep;68(9):901-2.

[6]. Thelma E Tupasi, Socorro Lupisan, Zenaida. Oxford Journals. Acute respiratory tract infection in children 2004 Nov-Dec; 12(8): S940-S942. 